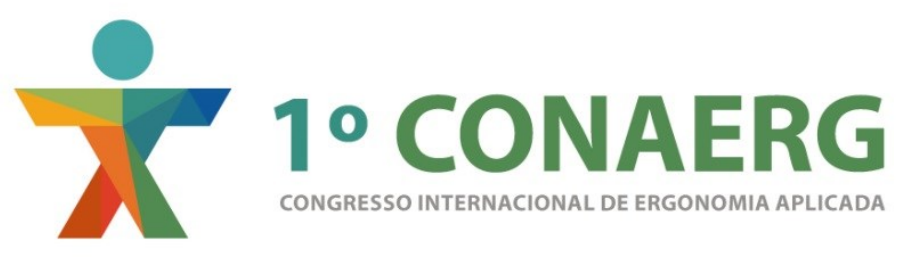

\title{
AVALIAÇÃO DOS AGENTES AMBIENTAIS DO POSTO DE TRABALHO DO MARTELETEIRO DA INDÚSTRIA DE MINERAÇÃO, SEGMENTO DE PEDRA BRITADA
}

\author{
Diogo Henrique Feijó Fialho (1); \\ Flávia Távora Maia (2); \\ Eduardo Henrique Queiroz Feijó de Melo (3) \\ Marcelo Márcio Soares (4)
}

Universidade Federal de Pernambuco - Programa de Pós-Graduação em Ergonomia (1), (2), (3) Especialista em Ergonomia e Segurança do Trabalho

(4) Doutor em Ergonomia

e-mails:diogofialho8@hotmail.com, flaviatavora@yahoo.com.br, eduardo.seguranca@yahoo.com.br, soaresmm@gmail.com

\begin{abstract}
RESUMO
Dentre as etapas de produção da mineração, segmento da pedra britada, particular importância deve ser dada ao posto de trabalho do operador de martelete, pelo fato da exposição a diversos fatores de riscos ambientais. Portanto, este trabalho teve como objetivo avaliar o posto de trabalho deste operador acerca dos aspectos ambientais. Foram realizadas avaliações qualitativas e quantitativa dos fatores de riscos presentes no ambiente. Os resultados das avaliações ambientais apresentaram condições nocivas e agressivas à saúde do trabalhador de acordo com limites legais de tolerância. Foram apresentadas ações cabíveis para eliminar ou mitigar tais condições.
\end{abstract}

\begin{abstract}
Among the steps of mining production, in the crushed stone sector, particular importance should be given to the job of the Gavel operator because of its exposure to various factors of environmental risk. Therefore, this study sets out to evaluate the job of this operator as to its environmental aspects. Qualitative and quantitative assessments of the risk factors present in the environment were made. The results of the environmental assessments showed that the conditions are hazardous and aggressive to the operator's health as laid down in the legal limits of tolerance to these conditions. Actions are suggested that can eliminate or mitigate them
\end{abstract}

\section{INTRODUÇÃO}

No Brasil, a busca, exploração e o aproveitamento dos seus recursos minerais tem íntima relação com a sua história, pois sempre contribuíram com importantes insumos para a economia nacional, fazendo parte da ocupação territorial e do contexto histórico nacional. A industrialização, o desenvolvimento e a formação de novos processos produtivos possibilitam 
o aumento da produção através da utilização de máquinas, equipamentos e métodos onde muitas vezes a ergonomia é esquecida.

Dentro do setor da mineração existe a exploração de agregados para a construção civil. A pedra britada, areia e cascalho, são os agregados mais comuns e mais consumidos no Brasil e no mundo. A rocha britada (brita) é uma das matérias primas essenciais para a fabricação do concreto, além de ser empregada em obras de saneamento, pavimentação, contenção, drenagem e lastro de ferrovias, entre outros.

Este setor gera grandes volumes de produção, apresenta beneficiamento simples, porém sendo necessário gerar grande volume devido ao baixo valor unitário. A produção de agregados para a construção civil, segundo o Departamento Nacional de Produção MineralDNPM, órgão criado em 1934 para gerir o setor de mineração no Brasil, é o segmento da indústria de mineração que comporta o maior número de empresas e trabalhadores e o único a existir em todos os estados brasileiros.

Atualmente, diversas ferramentas e avanços tecnológicos são utilizados para otimizar o processo produtivo e eliminar a exposição de trabalhadores a riscos. No entanto ainda existem atividades em que essas tecnologias têm sua aplicação inviabilizada ou inexistente, sendo o caso do posto de trabalho do operador de martelete nas pedreiras, também conhecido como "marteleteiro". Dentre as diversas etapas que envolvem o processo de produção de rocha britada, no que diz respeito a exposição a fatores de riscos ambientais, particular importância deve ser dada a este posto de trabalho, pelo fato da exposição a diversos riscos.

Por tanto este trabalho teve como objetivo analisar as condições ambientais de trabalho do Marteleteiro da indústria de mineração, segmento de pedra britada, através do reconhecimento qualitativo destes fatores de riscos bem como da avaliação quantitativa da exposição a riscos ambientais mensuráveis com limites de tolerância previsto pela legislação nacional. Cumpre chamar atenção para o fato dos fatores ambientais incluírem diretamente no desempenho dos trabalhadores sendo, portanto, uma das condições ergonômicas de análise do trabalho.

\section{CARACTERIZAÇÃO DO POSTO DE TRABALHO}

\subsection{Caracterização da Atividade}

O processo produtivo de uma pedreira compreende as seguintes etapas: limpeza da área, lavra, desmonte primário, desmonte secundário, britagem primária, britagem secundária, e a estocagem e transporte. A atividade do operador de martelete está localizada no desmonte secundário, que segue o desmonte primário, em função da detonação resultar em blocos com dimensões superiores a abertura do britador primário ou quando a detonação foi insuficiente. É então quando o marteleteiro realiza a perfuração dessas rochas superdimensionadas (matacões) para uma segunda detonação, também conhecido como fogacho (fogo secundário). O desmonte secundário também pode ocorrer mecanicamente utilizando rompedor hidráulico ou drop ball, quando possível.

$\mathrm{O}$ operador de martelete realiza a perfuração utilizando o equipamento perfuratriz rotativa manual pneumática, popularmente conhecido como martelete ou martelo rotativo, acionado através de compressores móveis a diesel. A atividade do marteleteiro compreende as seguintes etapas: transportar a perfuratriz manual, conectar a broca, de acordo com o furo, no martelo, ligar a mangueira do compressor, subir nos matacões de rocha, posicionar a perfuratriz e perfurar a rocha.

A atividade é realizada na mina a céu aberto, sujeito as variações climáticas, intempéries e radiação solar (Foto 01.). Somam-se a esta condição, a exposição ao ruído e a vibração proveniente do processo de perfuração das rochas com o martelete, a exposição à poeira, proveniente não só do processo de perfuração, mas também dos caminhões e máquinas que circulam nas proximidades, além do risco de queda por se deslocar sobre rochas irregulares, 
pontiagudas, escorregadias e algumas vezes instáveis. Além dos riscos ergonômicos no que diz respeito às posições adotadas para se realizar a atividade e ao transporte manual do martelete de $26 \mathrm{~kg}$.

Figura 1: Ambiente de trabalho do Marteleteiro de mineração, segmento da pedra britada.

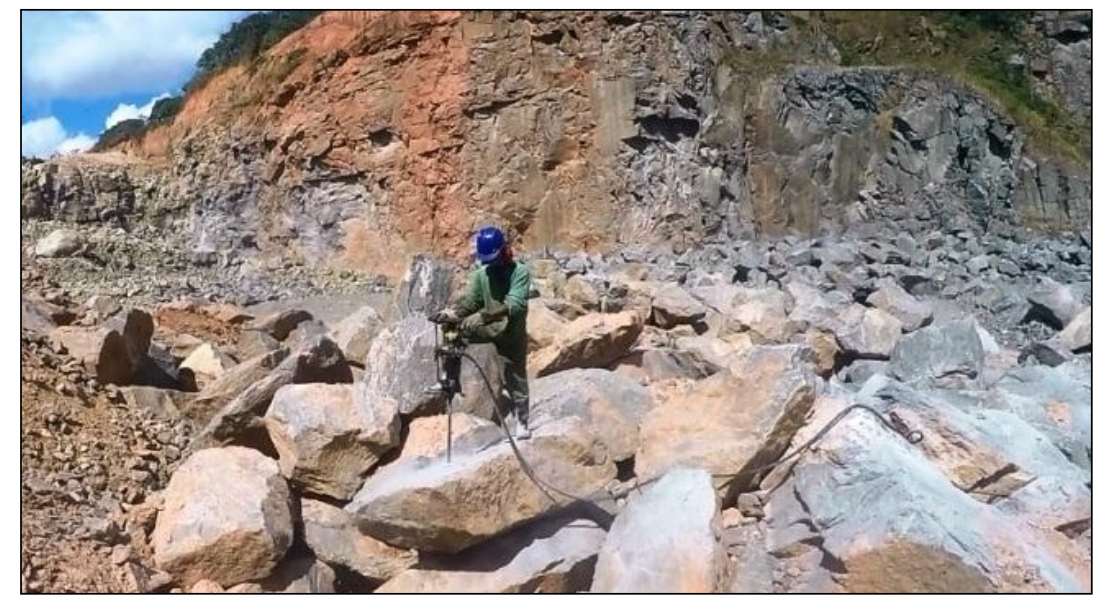

Fonte: Autores

\subsection{Descrição do equipamento martelo rotativo}

Perfuratrizes manuais são equipamentos utilizados em pedreiras para o desmonte de matacões. São transportadas manualmente a pequenas distâncias e executado os furos para a colocação do explosivo. A perfuração da rocha através da perfuratriz manual, martelete, é realizada pelos sincronismos de quatro movimentos realizados pelo equipamento: percussão ou impacto, rotação, avanço e limpeza.

A perfuratriz é um equipamento específico para fazer furos em profundidade e diâmetros variáveis. O equipamento é anexado à broca, haste metálica que possuem na extremidade materiais muito duros chamados de pastilhas, que escava a rocha perfurando e formando a cava.

A perfuratriz manual transmite um movimento de precursão e rotação à haste, mas, no entanto, é a pastilha que realiza a perfuração na rocha. Como possui material mais duro e resistente que a rocha, recebe e transmite o impacto e a rotação perfurando-a. Os martelos movidos a ar comprimido são os mais utilizados nas áreas de lavras das pedreiras de exploração de pedra granítica para a indústria da construção.

Para a operação da perfuratriz manual é necessário o acoplamento de um compressor. A função do compressor é elevar a pressão de certo volume de ar, admitido nas condições atmosféricas, até uma determinada pressão exigida para a execução dos trabalhos pelo ar comprimido. O equipamento realiza a compressão do ar ambiente que transforma um tipo de energia (elétrica ou diesel) em energia pneumática.

O ar comprimido é aplicado na perfuratriz para a percussão e para o sistema de limpeza. $O$ movimento do pistão é através da alternância do ar por uma válvula de controle. A limpeza é a retirada dos resíduos da rocha no furo através do jato de ar em um orifício na haste até a broca.

\section{ASPECTOS FÍSICOS DO POSTO DE TRABALHO}

Qualquer equipe de ergonomia, ao se deparar com demandas por análises ergonômicas, precisa estar habilitada a avaliar a situação de trabalho (ou de desenvolvimento de atividades 
quaisquer) sob os diversos aspectos que a condiciona e isto inclui o ambiente físico que a abriga (Viana \& Villarouco 2008).

Ainda de acordo com os mesmos autores, as tarefas e atividades que compõem o trabalho desenvolvem-se em ambientes que deveriam contribuir para o bem-estar do trabalhador, uma vez que passa boa parte de sua vida no ambiente laboral. Porém, sabe-se que há ambientes de trabalho que em nada contribuem com o trabalho, em especial com o trabalhador, por apresentarem problemas diversos, que podem ser de dimensionamento, acessibilidade, organização, layout, posto de trabalho e outros condicionantes físicos, ou ainda de sensações percebidas, que dizem respeito aos aspectos cognitivos e sensoriais experimentados pelos trabalhadores.

O ambiente salubre é aquele que contribui para a saúde e preservação da saúde do trabalhador, ou seja, caracterizado pela ausência de fatores agressivos (acústicos, térmicos, atmosféricos, tóxicos etc.). Como o próprio nome diz, insalubre é algo não salubre, doentio, que pode causar doenças ao trabalhador por conta de sua atividade laboral. A maioria dos fatores agressivos, presentes nos ambientes de trabalho, tem efeitos mediatos, porém cumulativos, agravando o quadro clínico de um trabalhador até os limites da sua resistência.

O exercício de trabalho em condições insalubres, acima dos limites de tolerância estabelecidos pelo Ministério do Trabalho, assegura a percepção de adicional de $40 \%$ (quarenta por cento), 20\% (vinte por cento) e 10\% (dez por cento), segundo se classifiquem nos graus máximo, médio e mínimo, respectivamente, conforme prevê artigo 192 da CLT.

A discriminação dos agentes considerados nocivos à saúde bem, como os limites de tolerância mencionados estão previstos nos anexos da Norma Regulamentadora NR-15, aprovada pela Portaria 3.214/78, com alterações posteriores.

\subsection{Calor (Sobre carga térmica)}

O calor pode ser gerado por fontes artificiais (caldeiras, fornos, etc.) ou fontes naturais, como é o caso dos trabalhos a céu aberto. Conforme o caso do posto de trabalho do marteleteiro, as atividades a céu aberto estão sujeitas as variações climáticas e intempéries, variação da radiação solar e outros fatores externos que influenciam como a velocidade e umidade relativa do ar.

De acordo com Medeiros (2014), a junção de um ambiente de trabalho que apresente uma condição de calor excessivo, com esforço físico extenuante realizado pelo trabalhador, somados com a utilização de roupas inadequadas, pode provocar copiosos transtornos induzidos pelo calor que vão desde uma leve fadiga transitória até complicações mais sérias.

A NR-15, Anexo 3, do MTE e a NHO-06 da FUNDACENTRO, fornece os parâmetros para medição do agente calor, além de determinar os tipos de aparelhos a serem utilizados nas medições. As normas estabelecem os limites de exposição na qual o trabalhador pode permanecer exposto sem que haja problemas com sua saúde.

A exposição ao calor deve ser avaliada através do "Índice de Bulbo Úmido Termômetro de Globo" - IBUTG definido pela equação que se segue:

Ambientes externos com carga solar:

$$
\text { - } \quad \text { IBUTG }=0,7 \mathrm{tbn}+0,1 \mathrm{tbs}+0,2 \mathrm{tg} \text { [Eq. 01] }
$$

Onde:

tbn = temperatura de bulbo úmido natural

$\operatorname{tg}=$ temperatura de globo

tbs $=$ temperatura de bulbo seco 
Para o Marteleteiro, por realizar atividade a céu aberto, será calculado o IBUTG externo com carga solar. O regime de trabalho definido no Quadro $n^{\circ} 1$ do Anexo 3 da NR-15 que define o IBUTG para trabalho contínuo (leve até 30,0; moderada até 26,7 e pesada até 25,0 ). Já de 15 minutos de trabalho com 45 minutos de descanso (leve de 31,5 a 32,2; moderada de 29,5 a $31,1$ e pesada de 28,0 a 30,0$)$.

A determinação do tipo de atividade (Leve, Moderada ou Pesada) é feita consultando-se o Quadro $n^{\circ} 3$ que define, por exemplo, trabalho leve como sentado, movimentos moderados com braços e tronco (digitando) - consumo de $100 \mathrm{Kcal} / \mathrm{h}$ - ou trabalho pesado como o trabalho intermitente de levantar, empurar ou arrastar pesos (p.ex. remoção com pá).

\subsection{Ruído}

A exposição ao ruído pode produzir danos irreversíveis à saúde do trabalhador em diversos níveis, afetando o sistema circulatório, aparelho digestivo, sistema endócrino, sistema imunológico, química sanguínea, função sexual e reprodutiva, porém, o mais estudado é o efeito lesivo sobre o aparelho auditivo provocando a perda da capacidade para ouvir (SOUZA, 1998). A PAIR (Perda Auditiva Induzida pelo Ruído) é um comprometimento auditivo passível de prevenção, podendo acarretar várias alterações importantes que interferem no cotidiano das pessoas. O ruído faz parte dos agentes ambientais insalubres que necessitam de uma avaliação quantitativa.

A Norma Regulamentadora $n^{\circ} 15$, que descreve as atividades, operações e agentes insalubres, inclusive seus limites de tolerância, estabelece em seu anexo I o tempo máximo diário permitido para determinada pressão sonora. Este anexo apresenta que o nível de ruído de $85 \mathrm{~dB}$ permite uma exposição máxima diária de até 8 horas. Já, em seu extremo, o ruído de $115 \mathrm{~dB}$ permite uma exposição de até 7 minutos.

A NHO 01 - Norma de Higiene Ocupacional da FUNDACENTRO define critérios e procedimentos técnicos, bem como os equipamentos para avaliação da exposição ocupacional ao ruído que implique risco potencial de surdez ocupacional.

\subsection{Vibração de Mãos e Braços}

A vibração pode ser classificada em dois tipos:

(a) Vibração de corpo inteiro ( $\mathrm{VCl}$ ): São aquelas transmitidas ao corpo do indivíduo sentado, em pé ou deitado e normalmente ocorrem em trabalho com máquinas pesadas como tratores, caminhões, aeronaves, máquinas de terraplanagem, máquinas industriais, grandes compressores, etc.

(b) Vibração de Mãos e Braços (VMB): São vibrações que atingem certas regiões do corpo, principalmente as mãos, braços e ombros. Normalmente ocorrem em operações com ferramentas manuais vibratórias: Marteletes, britadores, rebitadeiras, compactadores, politrizes, motosserras, lixadeiras, peneiras vibratórias, furadeiras, entre outros.

A exposição a vibração ocupacional, no caso do Marteleteiro, de mãos e braços, pode implicar risco à saúde, entre os quais a ocorrência da síndrome da vibração em mãos e braços (SVMB) ou a síndrome do dedo branco. De acordo com NHO-10 da FUNDACENTRO a Síndrome da vibração em mãos e braços (SVMB) corresponde à terminologia utilizada para se referir ao conjunto de sintomas de ordem vascular, neurológica, osteoarticular, muscular e outros, ocasionados pela exposição ocupacional à vibração em mãos e braços.

De acordo com a NR-15, anexo 08, o limite de exposição ocupacional diário para Vibração de Mãos e Braços (VMB) corresponde a um valor de aceleração resultante de exposição normalizada (aren) de $5 \mathrm{~m} / \mathrm{s}^{2}$. Ainda de acordo com a NR-15, para avaliação quantitativa da 
VMB, deve ser usado os critérios e procedimentos técnicos estabelecidos na NHO 10 - Norma de Higiene Ocupacional da FUNDACENTRO.

\subsection{Poeira com Sílica Livre Cristalizada}

A sílica, representada pelo símbolo $\mathrm{SiO} 2$, é um mineral muito duro que aparece em grande quantidade na natureza, pois é encontrada nas areias e na maioria das rochas. A sílica pode ser encontrada em formas cristalinas, tais como o quartzo, a tridimita, a cristobalita e a trípoli, ou na forma amorfa, como a sílica gel ou a sílica coloidal. A sílica livre cristalizada, cuja forma mais conhecida é o quartzo, é a sílica não combinada com nenhum elemento químico. Ela é a principal causadora da doença denominada silicose (FUNDACENTRO, 2010).

A silicose é uma doença incurável causada pelo acúmulo de poeira contendo sílica nos pulmões e a consequente reação dos tecidos pulmonares. Ela leva ao endurecimento dos pulmões e dificulta a respiração, podendo levar à morte. A poeira contendo sílica livre cristalizada pode aparecer em vários processos ou operações de diversos ramos industriais, tais como: cerâmica, vidro, metalurgia, fundição, siderurgia, química, construção civil e na mineração.

De acordo com a NR-15, Anexo 12, o limite de tolerância para poeira respirável, é expresso em $\mathrm{mg} / \mathrm{m}^{3}$, e é dado pela seguinte fórmula:

$$
\mathrm{LT}=\frac{8}{\% \text { quartzo }+2} \mathrm{mg} / \mathrm{m}^{3} \quad \text { [Eq. 02] }
$$

Sempre será entendido que "Quartzo" significa sílica livre cristalizada, ou seja, o limite de tolerância para poeira respirável será definida de acordo com a concentração de sílica livre cristalizada presente na amostra.

\subsection{Radiação Não lonizante}

A radiação não ionizante é o tipo de radiação que não possui energia suficiente para ionizar, ou seja, não possuem energia suficiente para arrancar elétrons de suas camadas por entre os átomos que se tornam via de deslocamento. As mais conhecidas são: luz visível; infravermelhos; ultravioletas; micro-ondas e laser. Apesar de não arrancar elétrons, possui o poder de quebrar algumas moléculas e ligações químicas.

A fonte mais comum da radiação não ionizante é o sol. Apesar de serem extremamente úteis para a manutenção da vida na terra e na manutenção direta do corpo humano ela gera alguns riscos dependendo da exposição. As radiações solares podem promover efeitos indesejados por meio de exposição excessiva a qual muitas vezes é característica da atividade laboral. Apesar de penetrarem superficialmente na pele os raios causam queimaduras solares e podem causar alterações nas células da pele que provocam o surgimento de câncer de pele.

A legislação brasileira, através da norma regulamentadora 21 , que trata do trabalho a céu aberto, aborda a obrigatoriedade de haver abrigos, ainda que rústicos, capazes de proteger os trabalhadores contra as intempéries da natureza. Outro item da NR 21 estabelece a exigência de medidas especiais contra insolação excessiva, por causa do sol.

\section{METODOLOGIA DA PESQUISA}

A pesquisa foi realizada em uma pedreira, mineradora de pedra britada, localizada na região metropolitana do Recife. Foi realizada uma primeira visita para observação de campo, filmagem e fotografia digital e entrevista livre com os marteleteiros, encarregados e engenheiros. A partir das coletas de dados, conhecimento do processo e das atividades desenvolvidas no posto de trabalho, foi realizado o reconhecimento dos fatores de riscos ambientais. 
Para avaliar a exposição ao calor, foi realizada uma medição do IBUTG externo utilizando um Monitor de sobrecarga térmica com os termômetros de bulbo úmido, bulbo seco e globo. Equipamento do fabricante Quest Technologies, modelo Questemp36, número de série TKH060019, devidamente calibrado.

Para avaliar o nível de pressão sonora (ruído), foi realizada uma medição com um medidor de nível de pressão sonora denominado audidosímetro, do fabricante Quest Technologies, modelo NoisePro DLX, com número de série NXN010056. Para a pré e pós calibração do aparelho, foi usado o calibrador acústico, também do fabricante Quest Technologies, modelo QC-10, com número de série QIH060066, devidamente calibardo. O aparelho operou na curva A e no circuito de ressonância lenta (slow), pois se trata de ruído contínuo e intermitente.

Para avaliação da poeira com determinação da concentração de sílica, foi utilizada bomba de vazão e amostrador (coletor) com cassete duplo para poeira com membrana de PVC de 05 $\mu \mathrm{m}$ de porosidade e $37 \mathrm{~mm}$ de diâmetro, referência SKC 225-8-01-1, bem como um ciclone para suporte do coletor, posicionado próximo a zona respiratória do Marteleteiro. A vazão média utilizada foi aprox. 1,7 L/min conforme método NIOSH 7602.

Para calibração da vazão foi utilizado o calibrador digital do fabricante TSI, modelo 4146, número de série 41460832 013, devidamente calibrado, bem como uma jarra de calibração. A bomba de amostragem utilizada foi a do fabricante AP Buck, modelo VSS-5, número de série VUS 1087. Após a coleta, a amostra foi encaminhada para análise no laboratório do Centro de Tecnologia SENAI-RJ Ambiental.

Para avaliação quantitativa da vibração de mãos e braços (VMB) foi utilizado medidor de vibração do fabricante Quest Technologies, modelo VI-410 devidamente calibrado. A medição foi realizada com o equipamento configurado para mãos e braços. Foi avaliada a aceleração resultante de exposição normalizada (AREN), através do posicionamento e fixação do sensor para mãos e braços (Dytran) no punho de pegada do equipamento martelete.

As avalições seguiram os procedimentos e critérios técnicos das Norma Regulamentadora $N^{\circ}$ 15 e Normas de Higiene Ocupacional da FUNDACENTRO. Os resultados das avaliações ambientais foram comparados com o limite de tolerância definido pela Norma Regulamentadora $\mathrm{N}^{\circ} 15$ do Ministério do Trabalho e Emprego.

\section{RESULTADO DAS AVALIAÇÕES}

\subsection{Sobrecarga Térmica (Calor)}

O resultado do IBUTG de $29,06^{\circ} \mathrm{C}$ está acima da máxima exposição permissível de $26,7^{\circ} \mathrm{C}$ para o trabalho contínuo, atividade moderada, conforme o Quadro $N^{\circ} 01$, do Anexo03 da Norma Regulamentadora No 15.

Por tanto, medidas preventivas devem ser adotadas pela empresa para minimizar os agravos a saúde do trabalhador:

- Disponibilização de bebidas frescas, com reposição suficiente de água;

- Fornecimento de vestimenta de trabalho adaptadas ao tipo de exposição e a natureza da atividade;

- Programação dos trabalhos, especialmente os mais pesados, nos períodos com condições térmicas mais amenas.

- Permissão de autolimitação;

- Informação e capacitação dos trabalhadores;

- Acompanhamento médico através do PCMSO. 


\subsection{Ruído}

O resultado da avaliação do nível de ruído $101,7 \mathrm{~dB}(\mathrm{~A})$. Este resultado apresentou valor acima da máxima exposição diária permissível de $85 \mathrm{~dB}(\mathrm{~A})$ para um período de trabalho de 8 horas conforme estabelece a Norma Regulamentadora $N^{\circ} 15$, Anexo 01 . Foi verificado que o trabalhador utilizava proteção auditiva constituído de dois abafadores em forma de concha, com certificado de aprovação (CA) no 4398, que de acordo com o laudo 023/2013 registrado no MTE, fornece uma atenuação do ruído, em nível de NRRsf, de $15 \mathrm{~dB}(\mathrm{~A})$, resultando por tanto, numa exposição de $86,7 \mathrm{~dB}(\mathrm{~A})$ que continua acima de limite de tolerância e não foi verificado evidências de treinamento para a utilização, guarda, conservação e manutenção deste EPI.

Por tanto, medidas preventivas devem ser adotadas pela empresa:

Intervenção na fonte emissora:

- Substituição do processo por máquina com rompedor hidráulico do tipo "Picão" com cabine fechada e climatizada;

Caso não seja possível a substituição do processo, outras medidas devem ser adotadas:

Intervenção sobre o trabalhador:

- Redução do tempo de exposição, através do rodízio de funcionários;

- Dimensionar um protetor auditivo com redução mínimo de $22 \mathrm{~dB}(\mathrm{~A})$;

- Treinamento e capacitação sobre as formas de prevenção;

- Acompanhamento médico através do PCMSO.

Dentre as medidas citadas, outra muito importante é a elaboração, execução e administração de um Programa de Conservação Auditiva (PCA) regulamentado pela NR 09 e NR 07, que busca promover em caráter preventivo, ações que evitem a aquisição e/ou evolução de perdas auditivas induzida pelo ruído ocupacional (PAIR). Este programa tem caráter multidisciplinar e deve integrar os trabalhadores expostos.

\subsection{Vibração de mãos e braços}

Para o cálculo da Aceleração Resultante Normalizada (AREN) foi considerado que o Marteleteiro executa 80 furos/dia e que cada furo dura em torno de 04 minutos. Por tanto resultando no tempo de exposição de 4 horas.

A definição do número de ciclos (furos) e o tempo da componente de exposição (tempo de furação da rocha) retrata uma estimativa das atividades observadas na data em que foram realizadas as avaliações e através de entrevista livre com os encarregados, tendo em vista a variabilidade do uso, e tempo de uso do equipamento em função das características da rocha e demanda de produção.

O resultado da aceleração resultante de exposição normalizada (aren) de $11,58 \mathrm{~m} / \mathrm{s} 2$ apresentou valor acima da máxima exposição diária de $5 \mathrm{~m} / \mathrm{s} 2$ definido no anexo 08 da NR15. Por tanto, adoção imediata de medidas corretivas são necessárias, conforme o Quadro 01 - Critério de julgamento e tomada de decisão da NHO-10 da FUNDACENTRO.

Para este nível de vibração, o tempo máximo de trabalho para manter a exposição em um limiar seguro abaixo do nível de ação, é de 20 minutos.

Medida corretiva imediata:

- Substituição do processo por máquina com rompedor hidráulico do tipo "Picão";

- Caso não seja possível a substituição do processo, outras medidas devem ser adotadas:

- Diminuição do tempo de exposição através do rodízio entre trabalhadores; 
- Utilização de luvas Anti-Vibração

- Monitoramento da Exposição;

- Treinamento e capacitação dos trabalhadores;

- Acompanhamento médico através do PCMSO.

Medidas de controle através da antecipação:

- Aquisição de equipamentos e acessórios novos - especificação do produto - avaliar possibilidades de escolha;

- Seleção de produtos que produzem menos vibração;

- Tarefas ou processos de trabalho novos;

- Implantação de procedimentos de manutenção voltados à redução dos níveis de vibração.

\subsection{Poeira Mineral com Sílica Livre Cristalina}

A avaliação de poeira apresentou um resultado de $1,83 \mathrm{mg} / \mathrm{m}^{3}$, com uma concentração de sílica de $15,18 \%$, resultando em um limite de tolerância de $0,47 \mathrm{mg} / \mathrm{m}^{3}$, conforme fórmula do Anexo 12 da NR-15.

$$
\mathrm{LT}=\frac{8}{\% \text { quartzo }+2} \mathrm{mg} / \mathrm{m}^{3} \Rightarrow \mathrm{LT}=\frac{8}{15,18+2} \mathrm{mg} / \mathrm{m}^{3} \Rightarrow \mathrm{LT}=0,47 \mathrm{mg} / \mathrm{m}^{3}
$$

Por tanto, a concentração de poeira está acima do limite de tolerância, definido pela NR-15, Anexo 12. Foi verificado que durante a avaliação o trabalhador utilizava respirador purificador de ar PFF 2 com certificado de aprovação (C A) número 14103, aprovado para proteção das vias respiratórias contra poeiras, névoas e fumos, conforme laudo $n^{\circ} 3168 / 2011$ registrado no MTE. Porém não foi identificado nenhuma evidência de treinamento dos Marteleteiros sobre a correta utilização, guarda, conservação, higienização, manutenção e limitações deste EPI.

Desta forma é necessário reduzir a exposição a níveis inferiores ao limite de tolerância, ou, se possível, eliminar a exposição.

\subsection{Trabalho a céu aberto (Radiação Solar)}

Conforme já descrito anteriormente, o trabalho do Marteleteiro ocorre a céu aberto, por tanto, exposto a radiação solar, praticamente toda a jornada de trabalho. A avaliação foi realizada qualitativamente, pois a legislação nacional não prever avaliações quantitativas para este tipo de exposição. Verificamos que os trabalhadores Marteleteiros não tinham abrigos capazes de protegê-los contra as radiações solares nos intervalos de trabalho, eles procuravam a sombra de alguma árvore, quando tinha, ou ficavam na pequena sombra do compressor. Portanto, medidas preventivas devem ser adotadas.

\subsection{Acidente do trabalho}

Dentre os riscos de acidente do trabalho, o mais eminente e constante é o risco de queda, devido o deslocamento dos Marteleteiros sobre rochas irregulares, pontiagudas e cortantes, escorregadias e algumas vezes instáveis, somado ao transporte manual do martelete que tem $26 \mathrm{~kg}$, e da mangueira do compressor.

Após a detonação com explosivos as rochas ficam aleatoriamente distribuídas abaixo da bancada. Algumas vezes assumem uma formação mais planas e outras vezes assumem formações montanhosas com rochas mais altas. Em entrevista livre com os Marteleteiros, os 
mesmos relataram que quanto mais alta a rocha, maior a dificuldade para carregar o martelete e consequentemente um risco de queda com maior probabilidade de lesão grave ou fatal. Ainda de acordo com os próprios Marteleteiros, esta situação era minimizada quando a máquina retroescavadeira fazia a nivelamento dessas rochas, porém, nem sempre isso era possível, devido a limitação de acesso da máquina a bancada.

\section{CONCLUSÃO}

Desta forma, baseando-se nos resultados das medições, bem como nas condições ambientais observadas, tipo de atividade, tipo de exposição e presença de agentes acima do limite de tolerância, pode-se afirmar que as atividades desenvolvidas pelo cargo de operador de martelete "marteleteiro" da mineração, segmento da pedra britada nas instalações da pedreira estudada, se enquadram nos critérios de exposição a riscos ambientais que acarretarão danos à saúde do trabalhador, portanto, caracterizadas como "Atividades ou Operações Insalubres" nos termos da Lei 6.514 de 22/12/1977, Portaria 3.214 de 08/07/1978 e Norma Regulamentadora № 15. Desta forma, medidas de controle são necessários.

\section{RECOMENDAÇÕES}

\subsection{Substituição do Posto de Trabalho pela Mecanização}

Seguindo uma hierarquia de recomendações para o posto de trabalho, a primeira delas seria a eliminação do posto de trabalho do Marteleteiro a partir da substituição do processo pela mecanização com máquinas já existentes no mercado, a exemplo do rompedor hidráulico também conhecido como "Picão" e/ou o sistema drop-ball que consiste em arremessar uma bola de aço com cerca de 5 toneladas sobre as rochas (Figura 11). São equipamentos que permitem quebrar a rocha através somente do esforço mecânico, não utilizando explosivos, o que garante segurança e economia na operação. Esta prática é muito mais sadia dos pontos de vista do meio ambiente e da segurança do trabalho, que o desmonte secundário. Entretanto exige carregadeiras hidráulicas e a bola, que não são equipamentos padrão para pedreiras, e ambos os processos tem alto custo.

Figura 2 - llustração da mecanização do processo. A = Rompedor hidráulico tipo "Picão"; B = Sistema dropball.

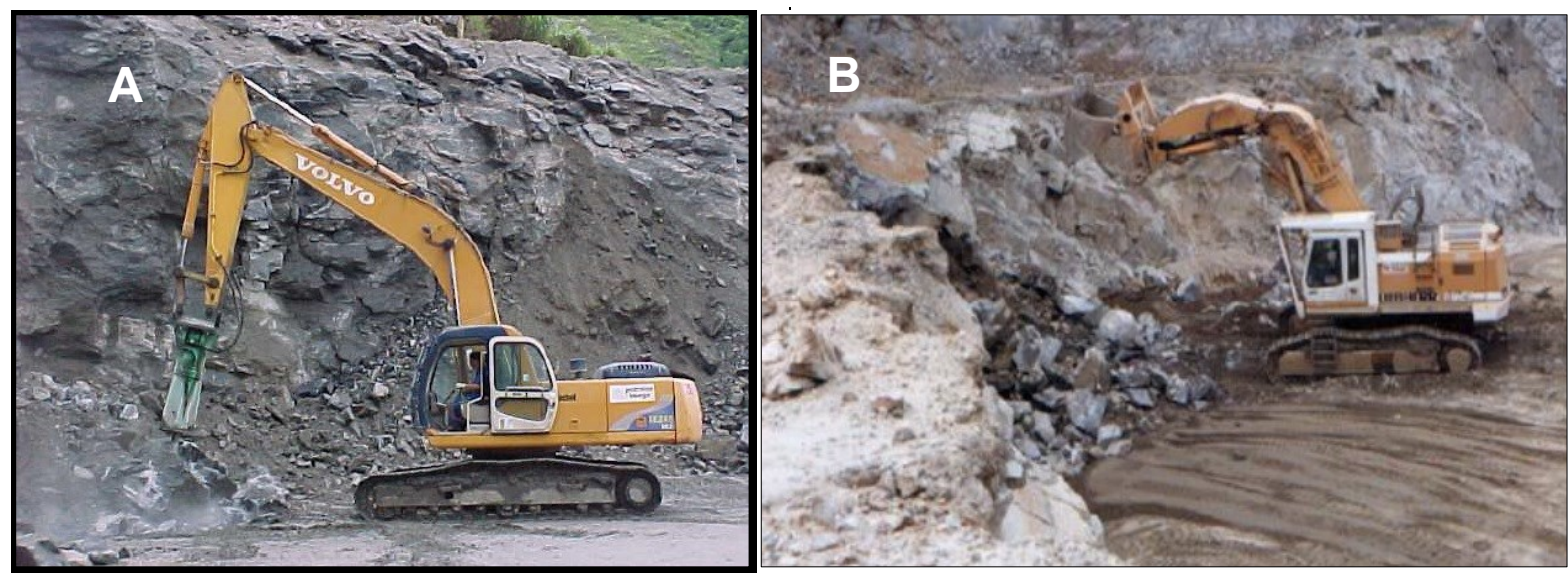

Fonte $=$ Silva, $(2005)$

Além do custo destes equipamentos, nem sempre será possível substituir $100 \%$ o posto de trabalho do Marteleteiro pelo rompedor hidráulico ou sistema drop-ball, tendo em vista a limitação de acesso destas máquinas as bancadas, seja por conta da formação assumida 
desses montantes de rochas após a detonação, inviabilizando a locomoção destas máquinas sobre as mesmas, limitando a operação apenas nas periferias, ou pela limitação da eficiência destas máquinas dependendo da dimensão e forma da rocha superdimensionada, que nem sempre o rompedor hidráulico ou sistema dropball, conseguem romper. Nestes casos será necessário o desmonte secundário e consequentemente a intervenção do Marteleteiro parta furação e posteriormente realizar a detonação da mesma.

Outra forma de reduzir a atividade manual do Marteleteiro é a modernização dos britadores primários (Figura 12), ou seja, ampliação da capacidade de britadores primários os quais possibilitam a entrada de rochas de maiores dimensões e, evitando desta forma, o desmonte secundário.

Figura 3 - Imagens ilustrativas da "boca" de britadores primários

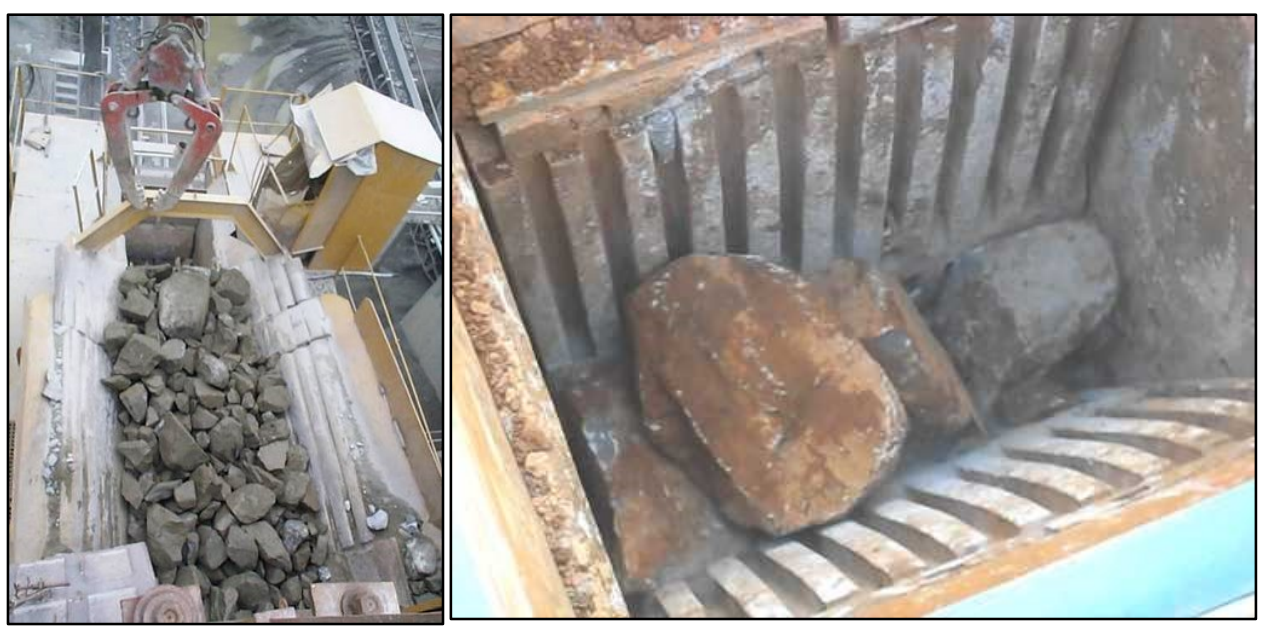

Fonte $=$ ANEPAC $($ www.anepac.org.br $)$

Os principais impactos positivos na mecanização do processo, além de eliminar um posto de trabalho com condições insalubres, permitem a redução de número de detonações e consequentemente de ultra lançamentos de fragmentos promovido pela detonação, vibrações no terreno, emissão de poeira e gases tóxicos na atmosfera e dos níveis de ruído, promovendo um maior conforto da comunidade circunvizinha.

\subsection{Recomendações mitigadoras}

$\mathrm{Na}$ falta de condições para a mecanização do processo, ou enquanto as mesmas estiverem sendo implantadas, ou quando não for possível a mecanizar $100 \%$ da atividade, ações mitigadoras devem ser adotadas no posto de trabalho:

\section{Ações referentes aos aspectos organizacionais}

- Elaboração e implantação de um Programa de Proteção Respiratória - PPR;

- Elaboração e implantação de um Programa de Conservação Auditiva - PCA;

- Disponibilização de bebidas frescas, com reposição suficiente de água;

- Fornecimento de vestimenta de trabalho adaptadas ao tipo de exposição e a natureza da atividade;

- Programação dos trabalhos, especialmente os mais pesados, nos períodos com condições térmicas mais amenas;

- Permissão de autolimitação (competência para decidir quando parar);

- Redução do tempo de exposição, através do rodízio de funcionários (operação máxima diária de 20min);

- Acompanhamento médico através do PCMSO. 
- Monitoramento das exposições através do Programa de Gerenciamento de Risco NR22;

Ações referentes aos aspectos físicos ambientais

- Instalação de tendas provisórias (lona) capazes de proteger os trabalhadores contra intempéries nos intervalos de trabalho;

- Estudo de viabilidade de substituição de equipamento por outro de menor dissipação de ruído (fornecedor);

- Enclausuramento parcial (do martelete) para minimizar a formação de poeira e emissão de ruído (projetação);

- Umidificação da pista e vias de circulação de máquinas e veículos a fim de minimizar a formação de poeira;

- Adotar uso imediato de protetor auditivo com redução mínimo de $22 \mathrm{~dB}(\mathrm{~A})$, conforme resultado da avaliação realizada;

Ações referentes aos aspectos de acidente do trabalho

- Nivelamento das rochas com o auxílio da retroescavadeira, de modo a mantê-las mais próximas do nível do terreno (quando possível) afim de evitar riscos de queda com maior potencialidade de dano;

- Calçado de segurança com sola antiderrapante/cravejada adequado para o tipo de trabalho;

- Adotar o uso de capacete de segurança com jugular para proteção da cabeça em caso de queda;

- Luva de segurança contra impactos mecânicos e pegada antiderrapante.

\section{REFERÊNCIAS BIBLIOGRÁFICAS}

BRASIL, Departamento Nacional de Produção Mineral. Sumário Mineral 2014 / Coordenadores Thiers Muniz Lima, Carlos Augusto Ramos Neves Brasília: DNPM, 2014. 141 p.: il.; 29 cm.

BRASIL. Decreto-Lei $n^{\circ}$ 5.452, de 1 de maio de 1943. Consolidação das Leis do Trabalho Disponível em: http://www.planalto.gov.br/ccivil_03/decreto-lei/Del5452.htm Acesso em: 13 jan. 2016.

BRASIL. Ministério do Trabalho e Emprego. Normas Regulamentadora de Segurança e Medicina do Trabalho - Disponível em: http://portal.mte.gov.br/legislacao/normas-regulamentadoras-1.htm Acesso em: 13 jan. 2016.

CENTRO DE TECNOLOGIA SENAI RJ AMBIENTAL - CTS. Instrução Técnica - Guia de amostragem de agentes químicos no ar. Rio de Janeiro, 2015.

FUNDACENTRO. Normas de Higiene Ocupacional - Disponível em: http://www.fundacentro.gov.br/biblioteca/normas-de-higiene-ocupacional

Acesso em: 13 jan. 2016.

SOUZA, Hilda Maria Montes Ribeiro de. Análise experimental dos níveis de ruído produzido por peça de mão de alta rotação em consultórios odontológicos: possibilidade de humanização do posto de trabalho do cirurgião dentista. [Doutorado] Fundação Oswaldo Cruz, Escola Nacional de Saúde $\quad$ Pública; $\quad 1998 . \quad 107 \quad$ p. $\quad$ Disponível $\quad$ em: http://portalteses.icict.fiocruz.br/transf.php?id=00010702\&/ng=pt\&nrm=iso\&script=thes_chap..Acesso em 10 de novembro 2015.

VIANA, V.; VILLAROUCO, V. Manual de apoio à disciplina: Ergonomia e Ambientes Físicos. 2008. (Desenvolvimento de material didático ou institucional - Apostila).

SILVA, J. A. P. A Mineração de Brita na Região Metropolitana do Rio de Janeiro. [Dissertação] Programa de Pós- Graduação em Engenharia Mineral do Departamento de Engenharia de Minas da Universidade Federal de Ouro Preto. Ouro Preto, 2005. 